UDK 623.454.8(612)

Biblid 0543-3657, 72 (2021)

God. LXXII, br. 1183, str. 35-51

Izvorni naučni rad

Primljen: 15.7.2021.

Prihvaćen: 8.8.2021.

doi: https://doi.org/10.18485/iipe_mp.2021.72.1183.2

Bogdan STOJANOVIĆ ${ }^{2}$

\title{
Strah od targetiranja kao glavni uzrok stopiranja libijskog programa nuklearnog naoružanja ${ }^{1}$
}

\section{SAŽETAK}

U radu se istražuje uzrok gašenja vojnog nuklearnog programa Libije, koji je trajao od uspostavljanja režima Muamera Gadafija pa sve do 2003. godine. Autor analizira faze razvoja nuklearnog programa, evidentirajući tri perioda - od pokušaja kupovine gotove nuklearne bombe, preko uspostavljanja saradnje sa drugim državama u cilju nabavke tehnologije za proizvodnju, do poslednje faze oslanjanja na sopstvene kapacitete uz spoljnu asistenciju i ilegalnu nabavku elemenata na crnom tržištu. Analizom praksi spoljnopolitičkog delovanja i unutrašnjih nuklearnih aktivnosti, autor kroz prizmu realističke paradigme pokušava da locira glavne uzroke stopiranja nuklearnog programa Libije. Odbacujući tezu o nedovoljnoj kadrovskoj sposobnosti, kao razlogu odustajanja i mogućnost ekonomskih sankcija da samostalno urode plodom, autor ističe strah od targetiranja kao glavni razlog napuštanja nuklearnih ambicija. Elaborirajući Gadafijev pragmatizam i razliku između deklarisanih i stvarnih namera, autor ističe značaj razumevanja prirode režima vođenog željom o prvoj arapskoj nuklearnoj bombi. Teorija hegemonske stabilnosti nudi osnov za teorijsko tumačenje libijskog ponašanja i konačnog odustajanja od nuklearnog programa. Rad otvara prostor za neke buduće akademske

${ }^{1}$ Autor je naučni saradnik u Institutu za međunarodnu politiku i privredu, Beograd. E-pošta: bogdan.stojanovic@diplomacy.bg.ac.rs.

${ }^{2}$ Rad je nastao u okviru naučnoistraživačkog projekta „Srbija i izazovi u međunarodnim odnosima 2021. godine", koji finansira Ministarstvo prosvete, nauke i tehnološkog razvoja Republike Srbije, a realizuje Institut za međunarodnu politiku i privredu tokom 2021. godine. 
analize, poput pitanja kada je nuklearno oružje sposobno da odvrati vojnu intervenciju i da li bi Libija bila napadnuta u slučaju nastavka rada na nuklearnoj bombi.

Ključne reči: Libija, nuklearni program, Muamer Gadafi, targetiranje, denuklearizacija, vojna intervencija.

\section{Istorijska težnja Muamera Gadafija}

Libija je postala nezavisna država 1951. godine pod kraljem Idrisom, pod čijim vođstvom je i potpisala Sporazum o neširenju nuklearnog naoružanja 1968. godine. Navedeni sporazum je od nuklearnog naoružanja stvorio neku vrstu tabua, pa se od otvorene težnje država za prestižom i moći koju nudi oružje apokalipse, prešlo na prikrivanje pravih namera o nuklearizaciji. ${ }^{3}$ Samo godinu dana nakon potpisivanja Sporazuma o neširenju nuklearnog oružja, libijski monarh je zbačen nakon državnog udara koji je predvodio tada mladi pukovnik Muamer Gadafi. ${ }^{4}$ Od uspostavljanja režima pukovnika Gadafija, pa u naredne tri decenije, Libija će aktivno pokušavati da se domogne statusa nuklearne sile. ${ }^{5} \mathrm{Od}$ dobijanja nezavisnosti, Libija nije imala teritorijalnih sporova niti ozbiljnih bezbednosnih pretnji u regionu, koje bi je podstakle na odluku da započne program nuklearnog naoružanja. Kao širi deo Bliskog istoka, regiona kome je razmišljanje kroz prizmu bezbednosne dileme imanentno, Libija je pod Gadafijevim vođstvom donela odluku o maksimizaciji sopstvene vojne moći, i to kroz nabavku nuklearnog naoružanja. Gadafi je otpočeo konfrontiranje sa Izraelom želeći da se nametne kao lider Arapa i osuđujući izraelski nuklearni monopol na Bliskom istoku. ${ }^{6}$ Političke aspiracije Muamera Gadafija dale su privlačnost nuklearnom oružju, dok je dodatni podsticaj iz bezbednosnog aspekta dao nuklearni status Izraela. Ministar spoljnih poslova Libije, Abdul Obeidi, rekao je da je postojalo nekoliko razloga za nuklearizaciju Libije, ali da je „najvažniji faktor izraelsko nuklearno oružje". ${ }^{7}$ Za Libiju nije bilo toliko važno protiv koga bi upotrebila bombu, već je jedino bilo važno da je proizvede. Veliko je pitanje da li je Izrael zaista bio pretnja opstanku Libije ili, što je verovatnije, poslužio kao

3 "Treaty on the Non-Proliferation of Nuclear Weapons", United Nations, 1968, Internet, https://www.un.org/disarmament/wmd/nuclear/npt/,16/5/2021.

${ }^{4} \mathrm{O}$ dolasku Gadafija na vlast u: Jon B. Alterman, "Libya and the U.S.: The Unique Libyan Case", Middle East Quarterly, Vol. 13, No. 1, Winter 2006, pp. 21-29.

${ }^{5}$ Elena Geleskul, "The History of the Libyan Nuclear Program: The Reasons for Failure", Security index, Vol. 15, No. 2, 2009, p. 139.

${ }^{6} \mathrm{Ibid}$.

${ }^{7}$ Målfrid Braut-Hegghammer, "Libyas Nuclear Turnaround: Perspectives from Tripoli”, Middle East Journal, Vol. 62, No. 1, Winter, 2008, p. 60. 
izgovor za libijsku nuklearizaciju. Kao ishodište potencijalne bezbednosne pretnje Gadafi je video i glavnog izraelskog saveznika SAD i njihovu imperijalnu težnju, ne samo ka Bliskom istoku gde im je Izrael glavni saveznik, već i globalno. ${ }^{8}$

To što nije bilo direktne bezbednosne pretnje prema Libiji, nije sprečilo pukovnika Gadafija da u kontekstu opštih regionalnih i hladnoratovskih rivaliteta otpočne akviziciju nuklearne bombe. Posmatrajući striktno kroz „naočare” realizma, u momentu pokretanja programa, za libijskog lidera nuklearno oružje je više imalo statusnu nego bezbednosnu funkciju. Kao lider koji je pokušavao da se nametne izvan nacionalnih okvira, vođen ideologijom panarabizma, Gadafi je težio stvaranju prve "arapske" nuklearne bombe. ${ }^{9}$ Iako nije bilo otvorenih bezbednosnih pretnji, celokupna napetost na severu Afrike i Bliskom istoku, kao i spoljnopolitička orijentacija da Libija bude lider arapskog sveta, navele su Gadafija da se upusti u avanturu dostizanja statusa nuklearne sile. Motivacije i podsticaje za takav poduhvat možemo tražiti u njegovoj percepciji sveta i načina na koji je video ulogu Libije $\mathrm{u}$ arapskom svetu. Od dolaska na vlast Gadafi je nesumnjivo želeo da Libiji obezbedi mesto u nuklearnom klubu, koji je tada bio rezervisan za mali broj država.

\section{Kupovina nuklearne bombe kao proa opcija}

Libijski nuklearni program ugrubo možemo podeliti u tri faze razvoja, $\mathrm{s}$ obzirom na dug vremenski period $\mathrm{u}$ kojem se odvijao i promenu metodologije u dostizanju istovetnog cilja - a to je nuklearna bomba. Prva faza programa obuhvata dvogodišnji period između 1969. i 1971. godine kada je Libija težila kupovini atomskog oružja. Na samom početku vladavine Gadafi je želeo da dođe do bombe najkraćim mogućim putem, iako su posednici nuklearne tehnologije ekspertizu i arsenale ljubomorno čuvale. U tu svrhu Libija se obratila Kini, kojoj je 1970. godine upućena ponuda za kupovinu kineske nuklearne bombe. ${ }^{10}$ Godinu dana kasnije libijski premijer Abdel Salam Jalud posetio je Peking, ali bezuspešno jer je Kina odbila da proda nuklearne bombe i samo ponudila ekspertsku pomoć. ${ }^{11}$ Kina je $u$ to vreme imala operativne nuklearne arsenale koji su

${ }^{8}$ Harald Muller, A European NonProliferation Policy. Prospects and Problems, Clarendon press, Oxford, 1987, p. 274.

${ }^{9}$ Joseph Cirincione, Jon B. Wolfsthal and Miriam Rajkumar, Deadly Arsenals. Tracking weapons of mass destruction, Carnegie Endowment for International Peace, Washington, 2002, p. 305.

${ }^{10}$ Ibid., p. 307.

${ }^{11}$ Leonard Spector and Jacqueline Smith, Nuclear ambitions: the spread of nuclear weapons 19891990, Westview Press, Oxford, 1990, p. 175. 
testirani još 1964. godine, ali su nominalno još uvek bili relativno skromni. Odluka kineskog rukovodstva da ne prodaje gotovo atomsko oružje razumljiva je iz aspekta racionalne kalkulacije države koja je uložila enormnu količinu novca, ljudskih resursa i vremena da bi samostalno razvila bombu. Teško je bilo zamisliti da će suverena država, koja je samostalno ovladala retkom tehnologijom i najmoćnijim oružjem koje je svet ikada video, olako prodati to oružje kao što bi prodala tenk, minobacač ili drugu vrstu vojnog naoružanja. Pripadnost nuklearnom klubu bila je ekskluzivitet rezervisan za mali broj najsposobnijih država sveta. Kada je libijskom lideru postalo jasno da je nemoguće kupiti gotovu nuklearnu bombu, odlučio se za samostalni nuklearni program.

Prema tvrdnji Keneta Timermana, Libija je navodno u početnoj fazi nuklearne ambicije kupila nekoliko stotina tona prirodnog uranijuma od francuskih rudnih kompanija u Nigeru, bez prijave nadležnoj Međunarodnoj agenciji za atomsku energiju. ${ }^{12}$ Prema potpisanom sporazumu Libija je pristupila međunarodnom režimu nuklearne neproliferacije koja je uključivala strogu kontrolu međunarodne inspekcije bilo kakvih nuklearnih aktivnosti. Doduše, Libija u tom momentu još uvek nije ratifikovala svoj potpis na navedeni sporazum. Miroljubiva upotreba nuklearne energije bila je dozvoljena, ali to je stvaralo dodatne poteškoće u kontrolisanju aktivnosti država koje su neretko pod izgovorom miroljubivih programa u pozadini skriveno razvijale nukelarno naoružanje.

Posle bezuspešnih pokušaja kupovine bombe, Libija je otpočela pregovore sa Sovjetskim Savezom o izgradnji prvog nuklearnog reaktora jer samostalno nije imala dovoljnog znanja za takav poduhvat. Početkom sedamdesetih godina Libija je imala dovoljno novca i bila je spremna da plati visoku cenu za pristup nuklearnoj tehnologiji i obuku libijskih stručnjaka koji bi u budućnosti samostalno upravljali postrojenjima. Porast prihoda od prodaje nafte zbog tada aktuelne naftne krize, omogućilo je Libiji da izdvoji enormne svote novca za veći zamah nuklearizaciji. Godine 1973. osnovana je Libijska komisija za nuklearnu energiju po ugledu na najrazvijenije države sveta, ali je $u$ tom momentu Libija već odustala od kupovine gotove nuklearne bombe. ${ }^{13}$

\section{Spoljnopolitičko koketiranje u potrazi za nuklearnom ekspertizom}

Period od 1971. do 1992. godine možemo okarakterisati kao drugu fazu libijskog programa koja se ogledala u pokušajima stvaranja zatvorenog

\footnotetext{
${ }^{12}$ Kenneth Timmerman, Weapons of Mass Destruction: the Cases of Iran, Syria, and Libya, Simon Wiesental Center, Los Angeles, 1992, p. 89.

${ }^{13}$ Målfrid Braut-Hegghammer, “Libyas Nuclear Turnaround: Perspectives from Tripoli”, op. cit., p. 62.
} 
gorivnog ciklusa "dual use" tehnologije koja je mogla biti preusmerena $\mathrm{u}$ vojne svrhe i proizvodnju plutonijuma. Druga faza nuklearnog programa zapravo je bilo sprovođenje strategije "nuklearnog vrdanja”, gde je Libija pod izgovorom civilnih tehnologija pokušavala da kreira bazu za razvoj nuklearnog oružja. U deceniji između 1971. i 1981. godine Libija je potpisala nekoliko međunarodnih ugovora sa Sovjetskim Savezom, Indijom, Pakistanom, Belgijom, Argentinom i Francuskom za tehnološko-kadrovsku pomoć u oblasti nuklearnih tehnologija. ${ }^{14}$

Libija je sa Sovjetskim Savezom ostvarila saradnju u nuklearnim pitanjima. Kao preduslov za tu saradnju Sovjetski Savez je istakao neophodnost ratifikacije Sporazuma o neširenju nuklearnog oružja, što je Libija uradila 1975. godine. Gadafi nije sproveo ratifikaciju sporazuma iz ubeđenja o značaju sprečavanja nuklearne neproliferacije, već upravo suprotno - da bi imao pristup civilnim nuklearnim tehnologijama. Ratifikacija mu je paradoksalno poslužila kao korak napred ka nuklearnoj bombi kroz saradnju sa Sovjetskim Savezom, tada kredibilnom nuklearnom supersilom. Libijski zvaničnici su 1977. godine posetili Moskvu i tražili pomoć u izgradnji nuklearnog teškovodnog reaktora na prirodni uranijum, fabrike za proizvodnju teške vode i postrojenja za separaciju plutonijuma. ${ }^{15}$ Libija je za ovu pomoć bila spremna da plati čitavih deset milijardi dolara, što je bila neverovatno visoka cifra ali što bi Libiji omogućilo civilnu tehnologiju koja relativno lako može biti preorijentisana u vojne svrhe. ${ }^{16}$ Sovjeti su se plašili nuklearizacije na Bliskom istoku iako su podržavali Gadafijev antiizraelski stav, pa su se odlučili da pomognu Libiji na njenom nuklearnom putu, ali ne u toj meri da može relativno lako proizvesti nuklearno oružje.

Odlučeno je da Sovjetski Savez pomogne Libiji kroz osnivanje istraživačkog centra i izgradnju lakovodnog nuklearnog reaktora sovjetske tehnologije na visoko obogaćeni uranijum snage $10 \mathrm{MW} .{ }^{17}$ Tim potezom Kremlj je libijski nuklearni program učinio zavisnim od sovjetske pomoći i stručnjaka koji su permanentno boravili u Tajuri, mestu gde se nalazio reaktor. Čitav kompleks u Tajuri bio je pod nadzorom ne samo Sovjetskog Saveza već i Međunarodne agencije za atomsku energiju, u skladu sa prihvaćenim obavezama koje propisuje Sporazum o neširenju nuklearnog

\footnotetext{
${ }^{14}$ Elena Geleskul, “The History of the Libyan Nuclear Program: The Reasons for Failure”, op. cit., p. 141.

${ }^{15}$ Ibid.

${ }^{16}$ Ibid.

${ }^{17}$ Roland Timerbaev, Stories of the Past: Memories of the Negotiations on Nonproliferation and Disarmament and Many Other Issues, ROSSPEN, Moscow, 2007, p. 28.
} 
naoružanja. Međutim, Gadafi je „sedeo" na više stolica kada je bila u pitanju strana asistencija u nuklearnom programu.

Prema Timermanu, Libija i Pakistan su na tajnom sastanku navodno potpisali pakt o izgradnji zajedničke nuklearne bombe, koristeći pakistansku ekspertizu koja je $\mathrm{u}$ tom momentu bila naprednija. ${ }^{18}$ Nikada nije zvanično ustanovljeno koliko novca je Libija zaista uložila u pakistanski nuklearni program. Saradnja sa Pakistanom otpočela je početkom sedamdesetih godina i bila je potpuno otvorena, bez skrivanja želje da se proizvede nuklearna bomba. Gadafi je istakao da je svetu potrebna ,,islamska bomba”, koja može biti proizvedena libijskim novcem od nafte i pakistanskim znanjem. Do kraja dekade, Libija je transferovala Pakistanu preko 100 tona „,̌̌utog kolača” (praškasti koncentrat uranijuma) koji je kupila u Nigeru. ${ }^{19}$ Da paradoks bude veći, Gadafi je istovremeno koketirao i sa Indijom, pakistanskim arhineprijateljem, $\mathrm{i}$ to nedugo nakon uspešnog testa indijske nuklearne bombe 1974. godine. Ambasador Indije u SAD je izjavio da je krajem 70-ih Gadafi „nudio novac Indiji uporediv njenom spoljnom dugu u zamenu za tehnologiju nuklearnog oružja".$^{20}$ Indija je odbila ovu ponudu, ali se $u$ julu 1978. godine sporazumom obavezala na pomoć Libiji $u$ postizanju nuklearne nezavisnosti u zamenu za jeftinu isporuku libijske nafte. ${ }^{21} \mathrm{U}$ svom političkom pragmatizmu Gadafi je činio sve kako bi se domogao tehnologije koja bi mu obezbedila nuklearnu bombu. Libija je takođe pokušavala da se domogne nuklearne tehnologije iz Francuske i Belgije, ali su ti pokušaji propali zbog snažnog pritiska SAD na svoje zapadnoevropske saveznike. ${ }^{22}$ Konfrontacija sa SAD je dovela do zabrane pristupa "zapadnim” nuklearnim tehnologijama, ali je Libija uložila ogroman napor da ostvari kontakt sa skoro svim državama sveta koje su u tom momentu raspolagale nuklearnom tehnologijom.

\section{Razvoj sopstvenih nuklearnih potencijala i međunarodna izolacija}

Nabavka gotove nuklearne bombe nije uspela, nabavka tehnologije koja bi mu omogućila laki prelazak sa civilnog na nuklearni program nije

${ }^{18}$ Kenneth Timmerman, Weapons of Mass Destruction: the Cases of Iran, Syria, and Libya, op. cit., p. 88.

${ }^{19}$ Leonard Weiss, "Pakistan: It's Deja Vu All Over Again", Bulletin of the Atomic Scientists, Vol. 60, No. 3, May-June 2004, p. 52

${ }^{20}$ Krajem 70-ih spoljni dug Indije je bio između 15 i 18 milijardi dolara. Videti: Keith Bradsher, "India Official Says Qaddafi Sought Atom-Arms Technology in '70s", New York Times, 10 October 1991.

${ }^{21}$ Wyn Q. Bowen, "Libya and nuclear proliferation: Stepping Back from the Brink", Adelphi Paper 380, The International Institute for Strategic Studies, London, 2006, p. 28.

$40{ }^{22}$ Harald Muller, A European NonProliferation Policy. Prospects and Problems, op. cit., p. 261. 
sprovedena u dovoljnoj meri da bi bila funkcionalna, što je Gadafija dovelo do uverenja kako jedino može da se osloni na sopstvene potencijale.

U tu svrhu Libija je organizovano slala hiljade svojih državljana na studije nuklearne fizike u Zapadnu Nemačku, SAD i Francusku. ${ }^{23}$ Američko „saplitanje" libijskog nuklearnog programa uključivalo je ne samo pritisak na zapadne saveznike da prekinu sve vrste saradnje u nuklearnim pitanjima sa Libijom već je išlo do te mere da je Reganova administracija zabranila libijskim studentima da studiraju nuklearne nauke u SAD. ${ }^{24} \mathrm{Kao}$ i prva faza pokušaja kupovine nuklearne bombe iz Kine druga faza obezbeđivanja tuđe tehnologije, koja bi dovela do proizvodnje bombe, zapala je u ćorsokak. Činjenica je da je Libija potpisala veliki broj međunarodnih ugovora $u$ oblasti nuklearne saradnje, ali je većina tih sporazuma ostala "mrtvo slovo na papiru". Sovjetski nuklearni reaktor u Tajuri nije mogao da proizvodi fisioni materijal za nuklearnu bombu, a osim toga bio je i nadziran od Međunarodne agencije za atomsku energiju, u skladu sa preuzetim međunarodnim obavezama. Saradnja sa zapadnoevropskim državama je propala, kao i saradnja sa dve međusobno neprijateljske države, Indijom i Pakistanom, jer su obe zemlje prepoznale opasnost libijskog pragmatizma.

Ostrakizam u međunarodnoj areni, od strane zapadnog bloka, dostigao je vrhunac nakon što je Libija označena kao sponzor terorističkih aktivnosti, uključujući i onih na tlu Evrope. Svakako najviše svetske pažnje privukao je slučaj iznad škotskog gradića Lokerbi kada je 1988. godine u eksploziji Pan Am-ovog aviona ukupno poginulo 270 ljudi. ${ }^{25} \mathrm{Za}$ teroristički napad je optužena Libija, a sam Gadafi je 2003. godine priznao umešanost i prihvatio plaćanje reparacija porodicama žrtava. Još 1986 . godine SAD su unilateralno uvele sankcije Libiji zbog toga što je označena kao sponzor terorizma, ali je nakon incidenta u Lokerbiju slučaj uzbunio i ostatak međunarodne zajednice. ${ }^{26}$ Godine 1992. Rezolucijom 748 Savet bezbednosti UN uveo je sankcije Libiji na vazdušni transport, nabavku oružja i ograničavanje kretanja određenih libijskih državljana. ${ }^{27}$ Sledeće godine Savet bezbednosti UN uveo je dodatne sankcije Libiji, čime je zamrznut deo njene imovine $u$ inostranstvu i zabranjena isporuka važne opreme u naftnoj industriji od koje

${ }^{23}$ John Cooley, "Qaddafi's Great Aim for Libya Is a Nuclear Capability of Its Own", Christian Science Monitor, 12 November 1980, p. 14.

24 “Libya Nuclear Chronology: 1980-1989”, NTI, February 2011, Internet, https:/ / media.nti. org/pdfs/libya_nuclear.pdf, 24/4/2021.

${ }^{25}$ Poginulo je 243 putnika, 16 članova posade i 11 ljudi koji su bili na zemlji. Videti: "Pan Am Flight 103 Fast Facts", CNN, 9 December 2019, Internet, https://edition.cnn.com/ 2013/09/26/world/pan-am-flight-103-fast-facts/index.html,15/4/2021.

${ }^{26}$ Ibid.

27 "Resolution 748", UN Security Council, 3063rd meeting, 31 March 1992, Internet, http://www.un.org/russian/documen/scresol/res1992/res748.htm, 25/4/2021. 
zavisi čitava libijska ekonomija. ${ }^{28}$ Zbog međunarodnog pritiska sa kojim se suočio, Gadafi više nije mogao da pomoć u oblasti nuklearne tehnologije traži među državama članicama UN, već isključivo na crnom tržištu.

Treća faza libijskog programa nuklearnog naoružanja uključuje samostalan razvoj tehnologije za proizvodnju nuklearnog oružja, ali ne bez pomoći spolja. Između 1995. godine, kada je uspostavljena veza sa ozloglašenom privatnom mrežom Abdula Kadira Kana koja je nudila svoje usluge u oblasti nuklearne ekspertize na „crnom tržištu”, i decembra 2003. godine kada je Gadafi definitivno prekinuo nuklearni program, Libija je bila najaktivnija u razvoju nuklearnog oružja. ${ }^{29}$ Ovaj period uključivao je ilegalne aktivnosti ka sticanju delova neophodnih za samostalnu proizvodnju nuklearne bombe. S obzirom na to da je Libija imala saradnju sa Pakistanom još sedamdesetih godina, uspostavljene veze omogućile su kontakt sa „ocem pakistanske nuklearne bombe" Abdulom Kadirom Kanom i njegovom ilegalnom mrežom. Prema izveštaju Međunarodne agencije za atomsku energiju, libijski zvaničnici su prvi sastanak sa Kanom imali još 1984. godine, koji nije urodio plodom..$^{30} \mathrm{Abdul} \mathrm{Kan} \mathrm{je} \mathrm{razvio} \mathrm{model} \mathrm{obogaćivanja} \mathrm{uranijuma}$ putem L1 i L2 centrifuga, koje je želeo da proda Libiji. Ugovor o isporuci centrifuga sa Kanom, potpisan je 1995. godine, a dve godine kasnije Libija je dobila 20 gotovih $L 1$ centrifuga za obogaćivanje uranijuma, kao i komponente da sama sastavi još 200 komada. ${ }^{31} \mathrm{U}$ septembru 2000. godine isporučene su dve $L 2$ centrifuge radi testiranja, a poručeno je još 10.000 komada čija masovna isporuka kreće dve godine kasnije. ${ }^{32}$ Mreža Abdula Kana bila je veoma razgranata i uključivala je firme i pojedince iz čak 13 država sveta, a za njene usluge Libija je platila preko 100 miliona dolara. ${ }^{33}$

Poslednja faza samostalnog razvoja nuklearnog oružja, kao i čitav nuklearni projekat Libije, definitivno je okončan u decembru 2003. godine kada se Muamer Gadafi javno odrekao nuklearnih ambicija i potpuno demontirao sva nuklearna postrojenja pod nadzorom Međunarodne agencije za atomsku energiju. Nakon inspekcije, Velika Brritanija je izvestila javnost da je Libija bila blizu razvoja nuklearnog naoružanja. ${ }^{34} \mathrm{U}$ izjavi se

28 "Resolution 883", UN Security Council, 3312nd meeting, 1 November 1993, Internet, http://www.un.org/russian/documen/scresol/res1993/res883.htm, 25/4/2021.

${ }^{29}$ Nuclear black markets: Pakistan, A.Q. Kahn and the rise of proliferation networks. A net assessment, The International Institute for Strategic Studies, London, 9 May 2007, p. 76.

${ }^{30}$ Elena Geleskul, "The History of the Libyan Nuclear Program: The Reasons for Failure", op. cit., p. 143.

${ }^{31}$ Ibid.

${ }^{32} \mathrm{Ibid}$.

${ }^{33}$ Ibid.

${ }^{34}$ Nigel Morris and Andrew Buncombe, "Libya Gives Up Nuclear and Chemical Weapons", The Independent, 20 December 2003, Internet, https://www.independent. 
kaže: „Tokom tri nedelje posete, našim stručnjacima su pokazani prikriveni uređaji i oprema te su im date informacije o naporima Libije na razvoju oružja za masovno uništenje tokom mnogih godina. Pukovnik Gadafi nije stekao sposobnost nuklearnog oružja, mada je bio blizu da je razvije". ${ }^{35}$

\section{Strah od targetiranja i kraj libijskih nuklearnih ambicija}

Proces nuklearnog odustajanja nije završen preko noći. Otpočeo je u maju 1999. godine kada je Libija pritisnuta sankcijama ponudila SAD odustajanje od nuklearnog programa zarad obustavljanja međunarodnog pritiska i izolacije u međunarodnim političkim i ekonomskim odnosima. Međunarodni pritisak značajno je ojačao nakon što je Libija optužena za teroristički napad na američki avion iznad Lokerbija 1988. godine i francuski avion nad Nigerom godinu dana kasnije. ${ }^{36}$ Sankcije Ujedinjenih nacija, krah cena nafte i visoka stopa inflacije 1994. godine, dovele su do ozbiljne unutrašnje uzdrmanosti režima. Dodatno „ulje na vatru” bilo je bujanje islamskog fundamentalizma u istočnom delu države koji je pravio ozbiljne probleme sve do 1998. godine. Od jedinog lidera koji se pita za sve u državi, Gadafi je došao u poziciju da mora braniti sopstvenu neprikosnovenost na unutrašnjem planu. Gadafi je shvatio da ideološki dogmatizam u percepciji međunarodnih odnosa mora zameniti pragmatizmom, koji je do tada bio isključivo rezervisan za ostvarivanje nuklearnih ambicija. Tako je Gadafi pokazao spremnost na pregovore sa Zapadom radi umanjivanja međunarodnog pritiska. Nuklearni program je bio važan element pregovora, tj. potreba da Libija odustane od svojih nuklearnih ambicija. Postrevolucionarna faza libijske spoljne politike otpočela je 90-ih godina, kulminiravši maja 1999. godine u pregovorima sa SAD kada je Gadafi obećao denuklearizaciju.

U periodu od 1999. do 2003. godine Libija je deklarativno iskazivala želju da napusti nuklearni program, ali je istovremeno putem mreže Abdula Kana nabavljala neophodne komponente za razvoj atomske bombe. SAD su izašle kao apsolutni pobednik Hladnog rata i poslednju deceniju XX veka provele kao usamljena supersila, uživajući u tzv. unipolarnom momentu. ${ }^{37}$

co.uk/news/world/politics/libya-gives-up-nuclear-and-chemical-weapons-83350.html, $5 / 5 / 2021$.

${ }^{35}$ Ibid.

${ }^{36}$ Målfrid Braut-Hegghammer, "Libyas Nuclear Turnaround: Perspectives from Tripoli”, op. cit., p. 65.

${ }^{37} \mathrm{O}$ analizi unipolarnog momenta videti: Charles Krauthammer, "The Unipolar Moment", Foreign Affairs, 1990, Internet, https://www.foreignaffairs.com/articles/1991-02-01/ unipolar-moment, 13/5/2021. 
Teroristički napad na američkoj teritoriji 11. septembra 2001. godine pokrenuo je globalni rat protiv terorizma, u vreme kada se Libija nalazila na listi država sponzora terorističkih akcija. Gledajući američku brutalnu intervenciju u Avganistanu 2001. godine i kasnije 2003. godine u Iraku, pukovnik Gadafi je rezonovao da Libija može biti sledeća meta intervencije, pod izgovorom sprečavanja proizvodnje oružja za masovno uništenje. SAD su se pripremale za napad na Irak krajem 2002. godine, a Gadafi je opravdano postao zabrinut da je on sledeća meta. Tadašnji premijer Italije, Silvio Berluskoni, izjavio je da ga je Gadafi nazvao i rekao da će uraditi „šta god oni žele", misleći na SAD, kako bi izbegao američki napad. ${ }^{38}$

Sankcije Saveta bezbednosti UN uvedene 1992, pa pojačane 1993. godine, kombinovane sa američkim sankcijama od 1986. godine, nanele su ozbiljan udarac libijskoj ekonomiji, baziranoj pretežno na izvozu nafte. Sprečavanje proizvodnje i prodaje libijske nafte na međunarodnom tržištu dovele su do ozbiljne ekonomske stagnacije, ali je veliko pitanje da li bi urodile plodom bez postojanja straha od targetiranja kod libijskog diktatora. Pojedini autori smatraju da su sankcije glavni razlog odustajanja Libije od nuklearnog programa i da Gadafi nije imao izbora osim da prekine program pod pretnjom ekonomskog kolapsa. ${ }^{39}$ Međutim, takav zaključak nije $u$ potpunosti ispravan jer je tokom trajanja sankcija Libija i dalje efektivno radila na razvoju nuklearne bombe, služeći se ilegalnim i tajnim nabavkama značajnih nuklearnih komponenti i ekspertiza. U maju 1999. godine Libija je ponudila gašenje svog nuklearnog programa, ali ga je ugasila tek $u$ decembru 2003. godine. U međuperiodu između 1999. i 2003. godine Libija je nastavila osetljivu razmenu informacija i nabavku tehnologija preko Kanove mreže. To govori da bi sankcije bez straha od targetiranja verovatno dovele do deklarativnog nuđenja stopiranja nuklearnog programa, što se desilo 1999. godine, ali bez stvarne akcije da se taj program prekine što se desilo četiri godine kasnije. „Vrdanje” u nuklearnim pitanjima i načelno prihvatanje međunarodnih obaveza, uz prikriveni rad na nuklearnoj bombi, pratile su čitav period nuklearnog programa Libije, što nam daje za pravo da ne poverujemo u scenario po kome bi Libija stopirala nuklearni program da nije bilo pretnje vojnom intervencijom.

Pojedini autori smatraju drugačije - da je nabavka nuklearnih komponenti preko ilegalne mreže služila za jačanje pregovaračke pozicije Libije u odnosima sa SAD. ${ }^{40}$ Takva argumentacija ide $u$ prilog tezi da je još

\footnotetext{
${ }^{38}$ Judith Miller, "How Qadhafi Lost His Groove", Wall Street Journal, 16 May 2006, Internet, https://www.wsj.com/articles/SB114773941211953610, 15/5/2021.

${ }^{39}$ Martin Indyk, "Iraq War Did Not Force Qadhafi's Hand", Financial Times, March 2004.

${ }^{40}$ Wyn Q. Bowen, "Libya and nuclear proliferation: Stepping Back from the Brink", op. cit.,
} 44 p. 67. 
maja 1999. godine Gadafi odlučio da potpuno prekine nuklearni program, ali je njegov nastavak značio ,jače karte” i veći ulog u pregovorima sa SAD. Prema takvom shvatanju, Libija zapravo nije imala stvarnu želju da sprovede nuklearni program posle 1999. godine, već je to služilo kao podizanje uloga. Ova teza je takođe problematična. Da nije postojala stvarna namera za proizvodnju bombe, nuklearni program ne bi dobio takav zamah i toliko ojačao u intenzitetu posle 1999. godine već bi se svodio na minorne aktivnosti u održavanju libijske „nuklearne pretnje”. Zapad je već znao za postojanje libijskog nuklearnog programa i pregovori su uključivali prekidanje istog, pa bi bilo potpuno iracionalno ulagati novac u hiljade centrifuga i novih postrojenja ako definitivno imate nameru da prekinete program. Nuklearne aktivnosti su zapravo bile najsnažnije u periodu nakon što je Libija obećala njihovo stopiranje.

Nastavak, pa čak i intenziviranje nuklearnog programa posle maja 1999. godine ne može biti samo u svrhu "polise osiguranja” za Libiju, posebno jer se radilo o super-tajnim nabavkama putem ilegalnih kanala. Otkrivanje takvih akcija Libije ne bi podiglo ulog u pregovorima, već bi potencijalno ugrozilo pregovore i stvorilo razlog za intervenciju. Jednostavno, zašto bi Gadafi Zapadu demonstrirao jačanje nuklearnih kapaciteta kockajući se da sve izgubi kao meta napada. Njemu nije bilo potrebno pregovaračko sredstvo $u$ vidu nuklearnog programa jer ga je već imao i bez „ilegalnih nabavki" posle 1999. godine. Izgledniji scenario bio je da je Gadafi i dalje želeo nuklearnu bombu, ali se opredelio za "strategiju vrdanja" javno zagovarajući pregovore kako bi olabavio međunarodni pritisak, dok je na drugoj strani tajno razvijao nuklearnu bombu. Kada je video destrukcije $u$ Avganistanu, i posebno Iraku, Gadafi je shvatio da je "vrag odneo šalu” i da će Libija biti naredni poligon za demonstraciju američke vojne moći. ${ }^{41}$

Mnoge komponente naručene na crnom tržištu nisu bile ni raspakovane, već su skupljale prašinu u skrivenim skladištima jer nije bilo dovoljno stručnjaka koji su raspolagali znanjem kako se te komponente koriste. Ipak, pogrešno bi bilo zaključiti da je Libija napustila nuklearni program iz razloga manjka kadrovskih sposobnosti. Gadafi je poznajući sopstvene kadrovske slabosti, dosta novca uložio u obrazovanje naučnog kadra $u$ inostranstvu. Kompleksnost upravljanja u Libiji, bez jasne podele nadležnosti, dodatno su otežavale nuklearni program. Neprikosnovenost pukovnika Gadafija, uz nejasne nadležnosti institucija čija se moć svodila na snagu ličnih odnosa sa Gadafijem i njegovim najbližim saradnicima, dovele su do tromosti programa i slabe implementacije na terenu. Pored

${ }^{41}$ Više o tome koliko je intervencija iz Iraka uticala na Libiju videti u: Målfrid BrautHegghammer, Unclear Physics: Why Iraq and Libya Failed to Build Nuclear Weapons, Cornell University Press, 2016. 
toga, Libija je raspolagala dovoljnim količinama novca koje je bila spremna da uloži u razvoj nuklearne bombe, dok je kadrovski potencijal konstantno jačao od početaka nuklearnog programa pa nadalje. Iako su postojale određene resursne prepreke, pre svega kadrovske i organizacione, one nisu bile razlog odustajanja Libije od programa nuklearnog naoružanja, već je to bio uvređeni strah od spoljne vojne intervencije poput onih u Avganistanu i Iraku.

Glavni argument teorije targetiranja potiče od opštije teze o hegemonskoj stabilnosti, podrazumevajući najmoćniju državu koja samostalno dominira svetskom politikom i sprovodi svoje namere diplomatijom, pritiscima ili ratom, ne obazirući se mnogo na postojeća međunarodna pravila. Enid Šetle je tvrdio da će države u eri postojanja hegemona težiti da izbegnu konfrontaciju sa državom hegemonom, što bi u ovom slučaju značilo napuštanje nuklearnog programa da ne biste postali meta intervencije. ${ }^{42}$ Jednostavna formula po kojoj se Libija odrekla nuklearnog oružja izbegavajući da postane meta hegemona, tj. SAD.

Kada su libijske diplomate otišle u London na proces pregovora, samo nedelju dana nakon terorističkih napada od 11. septembra 2001. godine, jasno im je saopšteno da sankcije UN (suspendovane rezolucijom), neće biti trajno ukinute sve dok Libija ne prekine program nuklearnog naoružanja. ${ }^{43}$ Ono što je $\mathrm{u}$ kombinaciji sa sankcijama dovelo do definitivne odluke jeste strah da će Libija biti poprište nove američke intervencije, nakon Avganistana i Iraka. Nakon napada na Irak, pod izgovorom da Sadam Husein pokušava da proizvede nuklearnu bombu, Gadafi je shvatio da je suviše opasno nastavljati tajni nuklearni program jer to može biti povod za američki napad. Nastavak sprovođenja strategije „nuklearnog vrdanja” gde bi se javno zagovarala antinuklearna posvećenost dok se bomba razvija $u$ tajnosti, bilo bi jednako hodu po ivici provalije, pa je doneta odluka o stopiranju svih nuklearnih aktivnosti. „Vrdanje” bi generisalo ogroman rizik da se takva aktivnost otkrije i kao posledicu izazove američku intervenciju poput one u Iraku. Osim toga, iz vojnog i logističkog aspekta Amerikancima nije bila strana intervencija u Libiji, budući da su još 1986. godine izvršili bombardovanje Tripolija i Bengazija. ${ }^{44}$

${ }^{42}$ Videti: Enid Schoettle, Postures for Non-Proliferation: Arms Limitations and Security Policies to Minimize Nuclear Proliferation, Taylor and Francis, London, 1979.

${ }^{43}$ Peter Beaumont, Kamal Ahmed, and Martin Bright, "The meeting that brought Libya in from the cold", The Guardian, 21 December 2003, Internet, https:/ /www.theguardian.com/ world/2003/dec/21/politics.libya, 4/5/2021.

${ }^{44}$ Wyn Q. Bowen, "Libya and nuclear proliferation: Stepping Back from the Brink", op. cit., 46 p. 11. 
Istovremeno sa prihvatanjem pregovora sa Zapadom, Gadafi se odricao i svoje ideologije panarabizma jer je shvatio da je potpuno izolovan $u$ međunarodnim odnosima. Palestinski lider i Gadafijev saveznik, Jaser Arafat, odrekao se radikalnih metoda, a Gadafi je morao da prati trend gušenja radikalizma u novom kontekstu potpune ekskomunikacije iz međunarodne zajednice. Stoga izjava da mu je "Afrika bliža u svakom pogledu nego Irak ili Sirija", najbolje govori o promeni identitetske paradigme kod Gadafija. ${ }^{45}$ Do 2003. godine Gadafi se javno odrekao arapskog nacionalizma i istakao želju da pristupi porodici civilizovanih naroda. Odricanje od programa nuklearnog oružja podstaknuto je, prema tome, i željom da se ostvare ekonomski i politički benefiti. Status „otpadničke države" nije bio izdrživ u eri globalne dominacije SAD i bez podrške Sovjetskog Saveza. Na odluku o denuklearizaciji uticala je kombinacija sankcija i političkih pritisaka uz „pokaznu vežbu” u Iraku koja je definitivno bila prelomni momenat u konstituisanju odluke. Američki predsednik Džordž Buš mlađi, eksplicitno je izjavio da su rat u Iraku i napori da se zaustavi nuklearni program Severne Koreje poslali jasnu poruku zemljama poput Libije da moraju napustiti programe za masovno uništenje. ${ }^{46}$ Spoljna politika Libije bila je racionalnije vođena, za razliku od 70-ih i 80-ih godina kada je bila vođena revolucionarnim ideološkim žarom bez jasne strategije. ${ }^{47}$ Nuklearna avantura Libije okončana je konačno 19. decembra 2003. godine zajedničkom izjavom sa SAD i Ujedinjenim Kraljevstvom o odustajanju od nuklearnog, biološkog i hemijskog naoružanja i restrikciji posedovanja balističkih raketa većeg dometa od 300 kilometara. ${ }^{48}$

\section{Zaključak}

Posle 11. septembra 2001. godine i terorističkog napada na tlu SAD, jedina supersila sveta $\mathrm{u}$ tom momentu stvorila je novu globalnu bezbednosnu agendu. Ta agenda uključivala je represivnije mehanizme prema svima koji su pomagali terorizam i prema svim državama koje su pokušavale ilegalno da steknu oružje za masovno uništenje. ${ }^{49}$ Libija se

${ }^{45}$ Gerald Butt, "Colonel Gaddafi's Libya”, BBC News, 15 May 2006, Internet, http://news. bbc.co.uk/2/hi/middle_east/3336059.stm, 21/4/2021.

${ }^{46}$ Nigel Morris and Andrew Buncombe, "Libya Gives Up Nuclear and Chemical Weapons", op. cit.

${ }^{47}$ Målfrid Braut-Hegghammer, "Libyas Nuclear Turnaround: Perspectives from Tripoli”, Middle East Journal, Vol. 62, No. 1, Winter, 2008, p. 57.

${ }^{48}$ John Hart and Shannon N. Kile, "Libya's renunciation of nuclear, biological and chemical weapons and ballistic missiles", in: SIPRI Yearbook 2005: Armaments, Disarmament and International Security, Oxford University Press, Oxford, p. 629.

${ }^{49}$ Wyn Q. Bowen, "Libya and nuclear proliferation: Stepping Back from the Brink", op. cit., p. 47. 
nalazila na obe liste, što je stvorilo izglednu mogućnost da bude predmet intervencije $u$ doglednoj budućnosti. Dugotrajna i snažna ambicija za dostizanje nuklearnog oružja na kraju nije imala rezultat razvoja libijske nuklearne bombe.

Bezbednosna dilema nije bila glavni podsticaj za otpočinjanje libijskog programa nuklearnog naoružanja već ideološka zanesenost liderstvom $u$ arapskom svetu, ali je glavni razlog stopiranja programa bilo uzrokovano bezbednosnom računicom. Čitavo posthladnoratovsko političko odlučivanje u Libiji svodilo se na kalkulaciju troškova i koristi, prilagođavajući se novonastalim međunarodnim okolnostima. Možemo zaključiti da je korišćenjem kombinovanih metoda „štapa i šargarepe” Libija primorana da odustane od proizvodnje nuklearnog oružja, pre svega zbog straha od američkog targetiranja. Politički i ekonomski benefiti koji bi bili posledica odustajanja, uz snažan strah od targetiranja, okončali su nuklearizaciju Libije. U tom momentu verovatno ispravna bezbednosna kalkulacija od strane Muamera Gadafija, ubrzo će se ispostaviti nedovoljnom da spreči intervenciju i smenu režima 2011. godine. Ova tema daje prostora za neke nove analize $\mathrm{u}$ kontekstu odustajanja od nuklearnog programa, posebno kada se uporedo posmatraju države koje su se odrekle oružja i pretrpele intervenciju (Irak i Libija), kao i one koje su ostale netaknute i pored nastavka nuklearnih aktivnosti (Severna Koreja i Iran). Deluje da je libijska denuklearizacija samo odložila intervencionističke namere Zapada.

Koliko će slučaj Libije biti koristan za neke države koje plediraju na razvijanje nuklearnog oružja u sadašnjem ili budućem periodu, posebna je oblast istraživanja. Da li stremljenje ka nuklearnom oružju dovodi do umanjenja bezbednosti poput Iraka ili Libije, ili je pak moguće govoriti o nuklearnom oružju kao vrsti odbrane od spoljne intervencije, o čemu može svedočiti nuklearni status Severne Koreje i možda Irana? Pravo pitanje na koje nemamo odgovor jeste - da li bi libijska nuklearna bomba uspela da spreči vojnu intervenciju u Libiji?

\section{Bibliografija}

“Libya Nuclear Chronology: 1980-1989”, NTI, February 2011, Internet, https://media.nti.org/pdfs/libya_nuclear.pdf, 24/4/2021.

"Pan Am Flight 103 Fast Facts", CNN, 9 December 2019, Internet, https:/ / edition.cnn.com/2013/09/26/world/pan-am-flight-103-fastfacts/index.html, 15/5/2021.

“Resolution 748", UN Security Council, 3063rd meeting, 31 March 1992, Internet, http://www.un.org/russian/documen/scresol/res1992/res 48 748.htm, 25/4/2021. 
“Resolution 883", UN Security Council, 3312nd meeting, 1 November 1993, Internet, http://www.un.org/russian/documen/scresol/res1993/ res883.htm, 25/4/2021.

Alterman, Jon B., "Libya and the U.S.: The Unique Libyan Case", Middle East Quarterly, Vol. 3, No. 1, Winter 2006, pp. 21-29.

Beaumont, Peter, Kamal, Ahmed, and Martin, Bright, "The meeting that brought Libya in from the cold", The Guardian, 21 December 2003, Internet, https://www.theguardian.com/world/2003/dec/21/politics. libya, $4 / 5 / 2021$.

Bowen, Q. Wyn, "Libya and nuclear proliferation: Stepping Back from the Brink", Adelphi Paper 380, The International Institute for Strategic Studies, London, 2006.

Bradsher, Keith, "India Official Says Qaddafi Sought Atom-Arms Technology in '70s", New York Times, 10 October 1991.

Braut-Hegghammer, Målfrid, "Libyas Nuclear Turnaround: Perspectives from Tripoli", Middle East Journal, Vol. 62, No. 1, Winter, 2008, pp. 55-72.

Braut-Hegghammer, Målfrid, Unclear Physics: Why Iraq and Libya Failed to Build Nuclear Weapons, Cornell University Press, 2016.

Butt, Gerald, "Colonel Gaddafi's Libya", BBC News, 15 May 2006, Internet, http://news.bbc.co.uk/2/hi/middle_east/3336059.stm, 21/4/2021.

Cirincione, Joseph, Wolfsthal, Jon B., and Rajkumar, Miriam, Deadly Arsenals. Tracking weapons of mass destruction, Carnegie Endowment for International Peace, Washington, 2002.

Cooley, John, “Qaddafi's Great Aim for Libya Is a Nuclear Capability of Its Own", Christian Science Monitor, 12 November 1980.

Geleskul, Elena, "The History of the Libyan Nuclear Program: The Reasons for Failure", Security index, Vol. 15, No. 2, 2009, pp. 139-145.

Hart, John and Kile, Shannon N., "Libya's renunciation of nuclear, biological and chemical weapons and ballistic missiles", in: SIPRI Yearbook 2005: Armaments, Disarmament and International Security, Oxford University Press, Oxford, pp. 629-648.

Homer-Dixon, Thomas F., Environment, Scarcity, and Violence, Princeton University Press, Princeton, 1999.

Indyk, Martin, "Iraq War Did Not Force Qadhafi's Hand", Financial Times, March 2004.

Krauthammer, Charles, "The Unipolar Moment", Foreign Affairs, 1990, Internet, https://www.foreignaffairs.com/articles/1991-02-01/unipolar-moment, 13/5/2021. 
Miller, Judith, "How Qadhafi Lost His Groove", Wall Street Journal, 16 May 2006, Internet, https://www.wsj.com/articles/SB114773941211953610, $15 / 5 / 2021$.

Morris, Nigel and Buncombe, Andrew, "Libya Gives Up Nuclear and Chemical Weapons", The Independent, 20 December 2003, Internet, https://www.independent.co.uk/news/world/politics/libya-givesup-nuclear-and-chemical-weapons-83350.html, 5/5/2021.

Muller, Harald, A European NonProliferation Policy. Prospects and Problems, Clarendon press, Oxford, 1987.

Nuclear black markets: Pakistan, A.Q. Kahn and the rise of proliferation networks. A net assessment, The International Institute for Strategic Studies, London, 9 May 2007.

Spector, Leonard and Smith, Jacqueline, Nuclear ambitions: the spread of nuclear weapons 1989-1990, Westview Press, Oxford, 1990.

Schoettle, Enid, Postures for Non-Proliferation: Arms Limitations and Security Policies to Minimize Nuclear Proliferation, Taylor and Francis, London, 1979.

Timerbaev, Roland, Stories of the Past: Memories of the Negotiations on Nonproliferation and Disarmament and Many Other Issues, ROSSPEN, Moscow, 2007.

Weiss, Leonard, "Pakistan: It's Deja Vu All Over Again", Bulletin of the Atomic Scientists, Vol. 60, No. 3, May-June 2004, pp. 52-59.

Timmerman, Kenneth, Weapons of Mass Destruction: the Cases of Iran, Syria, and Libya, Simon Wiesental Center, Los Angeles, 1992. 


\section{FEAR OF TARGETING AS THE MAIN CAUSE FOR STOPPING LIBYA'S NUCLEAR WEAPONS PROGRAM}

\section{ABSTRACT}

This article investigates the causes of the shutdown of Libya's nuclear weapons program, which lasted from the establishment of Muammar Gaddafi's regime until 2003. The author analyses the phases of the nuclear weapons program, observing three periods, from attempts to purchase a produced nuclear bomb, through establishing cooperation with other countries in order to procure production technology, to the last phase of relying on own capacities with external assistance and illegal procurement of nuclear elements on the black market. By analysing the practices of foreign policy and internal nuclear activities, the author tries to locate the main causes of the stoppage of Libya's nuclear program through the prism of a realistic paradigm. Rejecting the thesis of insufficient personnel capacity as a reason for stopping the nuclear program and the possibility of economic sanctions to deliver results, the author emphasizes the fear of targeting as the main cause for abandoning nuclear ambitions. Elaborating on Gaddafi's pragmatism and the difference between declared and real intentions, the author emphasizes the importance of understanding the nature of the regime driven by the desire for the first Arab nuclear bomb. The theory of hegemonic stability offers a basis for a theoretical interpretation of Libyan behaviour and the final abandonment of the nuclear weapon program. This article opens up space for future academic analysis, such as the issue of the capability of nuclear weapons to deter military intervention and whether Libya would be attacked in the case of further work on the nuclear bomb.

Keywords: Libya, nuclear program, Muammar Gaddafi, targeting, denuclearization, military intervention. 